\title{
DEVELOPING OF A PARKING DEMAND MODEL FOR PUBLIC HOSPITALS IN CONGESTED CITIES
}

\author{
Metwally G. M. Altaher \\ Professor of Highway and Airport Engineering, Faculty of Engineering, \\ Zagazig University, Egypt \\ Mohamed Abdelghany Elsayed
}

Associate Professor of Highway and Airport Engineering, Faculty of Engineering, Zagazig University, Egypt

\begin{abstract}
Ali Ramadan Ibrahim
Assistant Lecturer of Highway and Airport Engineering, Faculty of Engineering, Zagazig University, Egypt
\end{abstract}

\begin{abstract}
Zagazig city is the third congested city in Egypt. More than million daily person trips are moving in Zagazig streets. It is the center of activities of Sharkia governorate in addition to its high number of population which reaches to about 0.6 million capita according to 2018(population density $=3655$ capita $/ \mathrm{km}^{2}$ of urban area). Also the population of Zagazig city continually to increases with a notable rate (1.7\%) causing the need of increasing numbers of facilities including health facility. The traffic volume needing the health facility is often uses private motor regarding to the nature of the patients and their companions. About 6 big public hospitals are located within Zagazig city in addition to about 100 unit of private hospitals, polyclinics and medical centers which attract a huge volume of traffic causing a high demand for parking spaces. Egyptian code defines parking rate of private hospitals. Until now there is no parking rate for public hospitals. This paper aims at analyzing the parking characteristics of public hospitals as well as developing its parking demand model. To achieve these objectives, three main hospitals in Zagazig city were selected for including : (a)- compound Zagazig university hospitals 1, (b)-compound Zagazig university hospitals 2, and (c)- El Ahrar hospital. Parking data were collected and used to model parking demand based on a comprehensive analysis. Through analyzing the results, it can be concluded that parking rates of public hospitals based on either bed or area are noticeably lower than the identical values given by ITE. Also, the rate of parking per bed ranges between 0.292 and 0.421 with an average of 0.333. While the average rate of parking per $100 \mathrm{~m}^{2}$ of total gross floor area is found to be 0.509 .
\end{abstract}


Keywords: Parking demand, Hospitals, Zagazig city, and Egypt.

Cite this Article: Metwally G. M. Altaher, Mohamed Abdelghany Elsayed and Ali Ramadan Ibrahim, Developing of a Parking Demand Model for Public Hospitals in Congested Cities. International Journal of Civil Engineering and Technology, 11(5), 2020, pp. 47-56.

https://iaeme.com/Home/issue/IJCIET?Volume=11\&Issue=5

\section{INTRODUCTION AND LITERATURE REVIEW}

Zagazig city is considered the center of activities in Sharkia governorate. So, it is the largest generator of trips in the Sharkia governorate. Zagazig city is considered a congested city from the traffic point of view. That is Metwally et al. (2019) evaluated the congestion level in Zagazig city [1]. Average travel speed as well as average running speed were measured on six main streets in Zagazig city. It was found that extra times of travel time had been ranged between $51.85 \%$ and $73.20 \%$ of their corresponding free flow time. So, according to Tom Tom (2019) [2], it was concluded that Zagazig city is a congested city. It is noted that illegal on-street parking is a main problem of the city which causing many harmful effects such as decreasing travel speed, increasing delay times, and decreasing operating level of services for most of Zagazig network streets. The absence of specified optimum parking rates of Zagazig city and consequently the unsuitable and random number, and places of parking at Zagazig city may be the cause. So, developing parking rate in the city has become necessity.

The large population and the notable rate of population growth of Zagazig city needs moving of vehicles for supplying different activities such as social, medical, entertainment. Health activity is one of the most important facilities. Zagazig city have a huge number of private hospitals, public hospitals, polyclinics and medical centers reaches more than 100 unit. Transportation of patients in Egypt is of a special nature and tends to use private vehicles (private car, taxi, and microbus ) which transporting about $53.33 \%$ of total daily trips of Zagazig city based on Metwally et al. (2019) [3]. Each private vehicle enters the hospital needs parking place. So, defining accurate parking rates for hospital activity sector in Zagazig city is of most importance.

Several researchers studied developing of parking demand rates for different activities at different cities. Okil, et al. (2019) developed parking demand model for universities private, and higher institutes, schools, wedding occasions halls, and consolation occasions halls in Greater Cairo region, Egypt [4]. It was found that parking rates based on space per student were $0.02,0.10,0.066,0.044,0.115$, and 0.072 space per student for public universities, private universities, higher institutes, secondary public schools, primary public schools, secondary private schools, and primary public schools, respectively. The authors recommended also that all land uses in Egypt should be studied [4]. Suthanaya (2017) analyzed parking characteristics and created parking demand models for car and motor cycle [5]. In this paper, The author found that the number of beds for class room 1 was the best variable of car parking demand and the number of hospital's employees was the best predictor for motor cycle parking demand. Models of parking rate of public hospitals by Suthanaya (2017) were $\mathrm{Y}=9.224+3.27 \mathrm{X} 3$ with $\mathrm{R}^{2}$ of 0.774 for private car and $\mathrm{Y}=124.801+0.940 \mathrm{X} 9$ with $\mathrm{R}^{2}$ of 0.838 for motor cycle. Where; $\mathrm{Y}$ is parking demand, $\mathrm{X} 3$ number of beds for class room 1 , and X9 number of employees. Many countries established parking rates manual to reflect their local conditions such as the UAE where (Department of Transportation Abu Dhabi, 2012) [6] provided a manual for parking. Department of Transportation Abu Dhabi defines parking rates of different classification of hospitals. Parking rates of Abu Dhabi manual is 0.281 vehicle per bed for government hospitals. In the case of private hospitals; this rate is 0.218 vehicle per bed. While in the case of private clinics; this rate is 0.370 vehicle per 
doctor. Institute of transportation engineers (ITE) established manual to determine parking rates for different land uses. Parking rate of hospital based on ITE is 3.47 vehicle per bed for urban region [7]. Center, D. R. (1994) recommended to define parking rate for hospital activities (public, and private)[8]. Egyptian code (2007) defines parking rate of private hospitals. This rate is 1.5 vehicle per bed[9]. Until now there is no parking rate for public hospital. In Punjab, Khan, et al. (2015) created parking demand model for hospitals by incorporating four public and two private hospitals. It was found that the number of beds is a best independent variable than area of hospitals [10]. Khan, et al. (2015) recommended that a separate parking demand model for private and public hospitals needs to be developed. In New Zealand and UK, Douglass and Abley (2011) established parking demand study for hospital. They found that the design parking demand (spaces $/ 100 \mathrm{~m}^{2} \mathrm{GFA}$ ) for hospital is affected by the gross floor area ratio (GFA). For GFA 1-500 $\mathrm{m}^{2}$, the average parking demand is 3.89 (New Zealand) and 4.73 (UK). For GFA 501-1000 $\mathrm{m}^{2}$, the average parking demand is 5.87 (New Zealand) and 4.23 (UK)[11].

The main objectives of this study are analyzing the parking characteristics of public hospitals as well as developing its parking demand model at congested cities. Zagazig city was selected as a case study due to its pre-mentioned characteristics. Public hospitals is selected to be the first of all different selected activities of studying parking rates because of its huge number of units spread all over Zagazig city. To achieve these objectives, a comprehensive experimental program was designed and implemented. The next section presents thoroughly explanation of study methodology.

\section{STUDY METHODOLOGY}

To achieve the objectives of this paper, several successive activities were performed. The first activity was collecting all previous studies which related to analysis and developing parking rates of health activates. The second activity was selecting Zagazig city as a congested city based on the considerations explained in the previous section. The third activity was selecting public hospital as a land use type because of its huge number of units spread all over Zagazig city. The fourth activity was selecting sample size according to ITE. Three public hospitals were selected including: (a) - compound Zagazig university hospitals 1, (b) - compound Zagazig university hospitals 2, and (c) - El Ahrar hospital. Figure (1) illustrates locations of the selected public hospitals. The Fifth activity was designing preliminary questionnaires to count traffic parking. The preliminary questionnaires was tested and adjusted to be in the final form as shown in Figures (2). Inventory data of sample including their area and number of beds were collected using form shown in Figures (3).

Parking characteristics were collected for every selected site through two weekdays. The site parking demand counts were conducted every one hour during the 8:00 AM to 4:00 PM (8hours) for each site. Number of private vehicles parked in the parking area of the investigated hospitals were manually counted. Inventory data were collected from the hospital's administrative records. The last stage of work was discussion and analysis of collecting data to get study conclusions and recommendations. 
Developing of a Parking Demand Model for Public Hospitals in Congested Cities

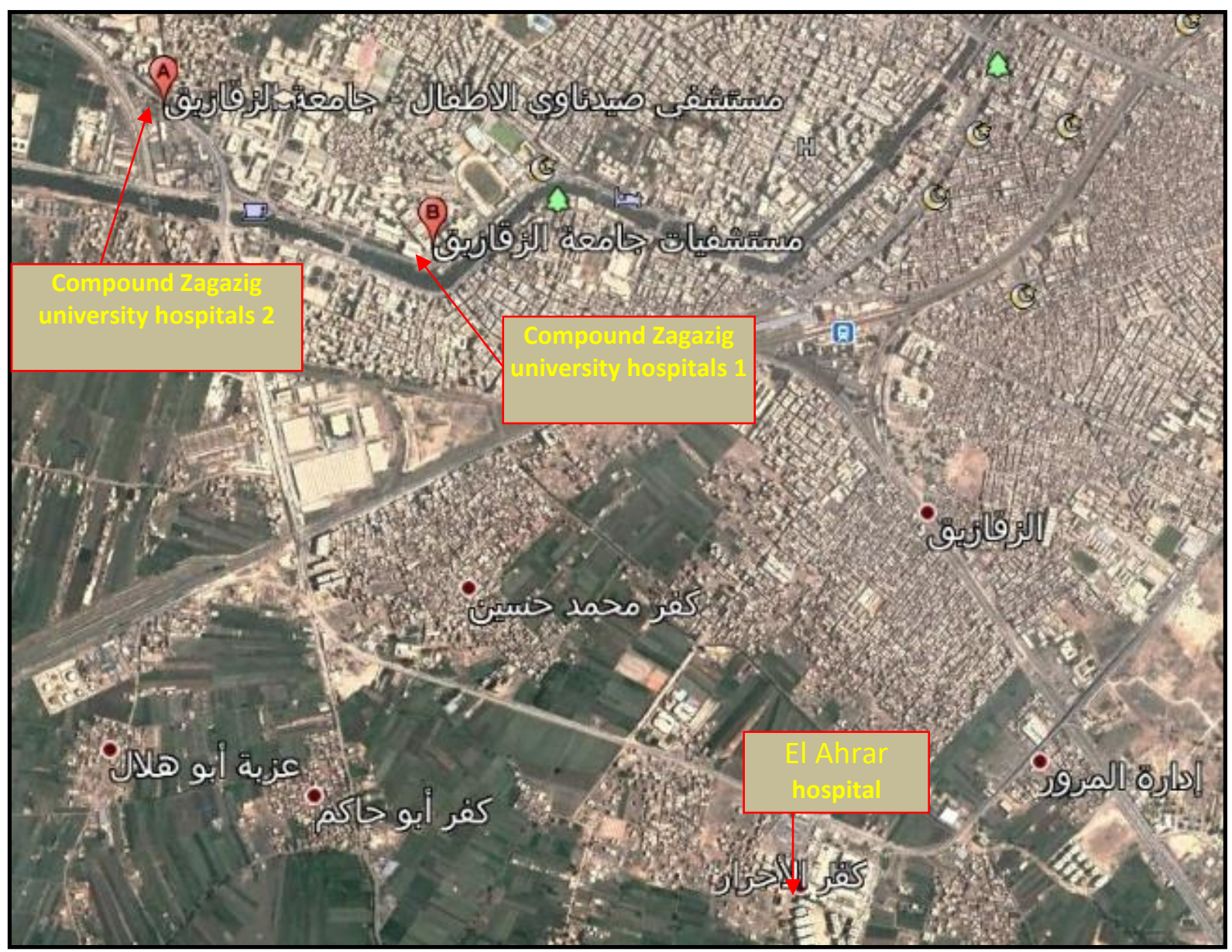

Figure 1 Locations of investigated public hospitals in Zagazig city, Egypt

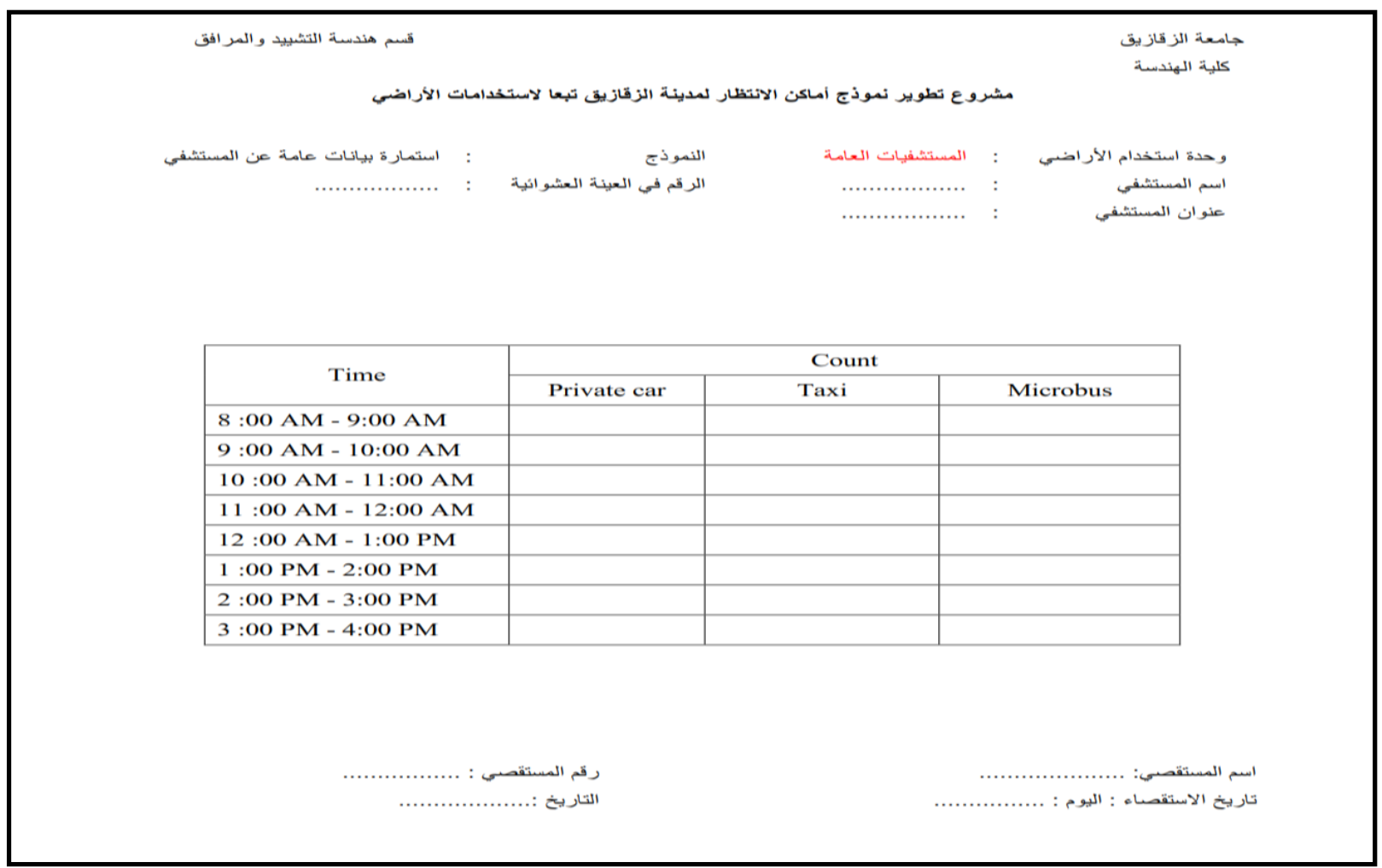

Figure 2 Parking count survey form designed for parking demand rate of investigated public hospitals in Zagazig city, Egypt 

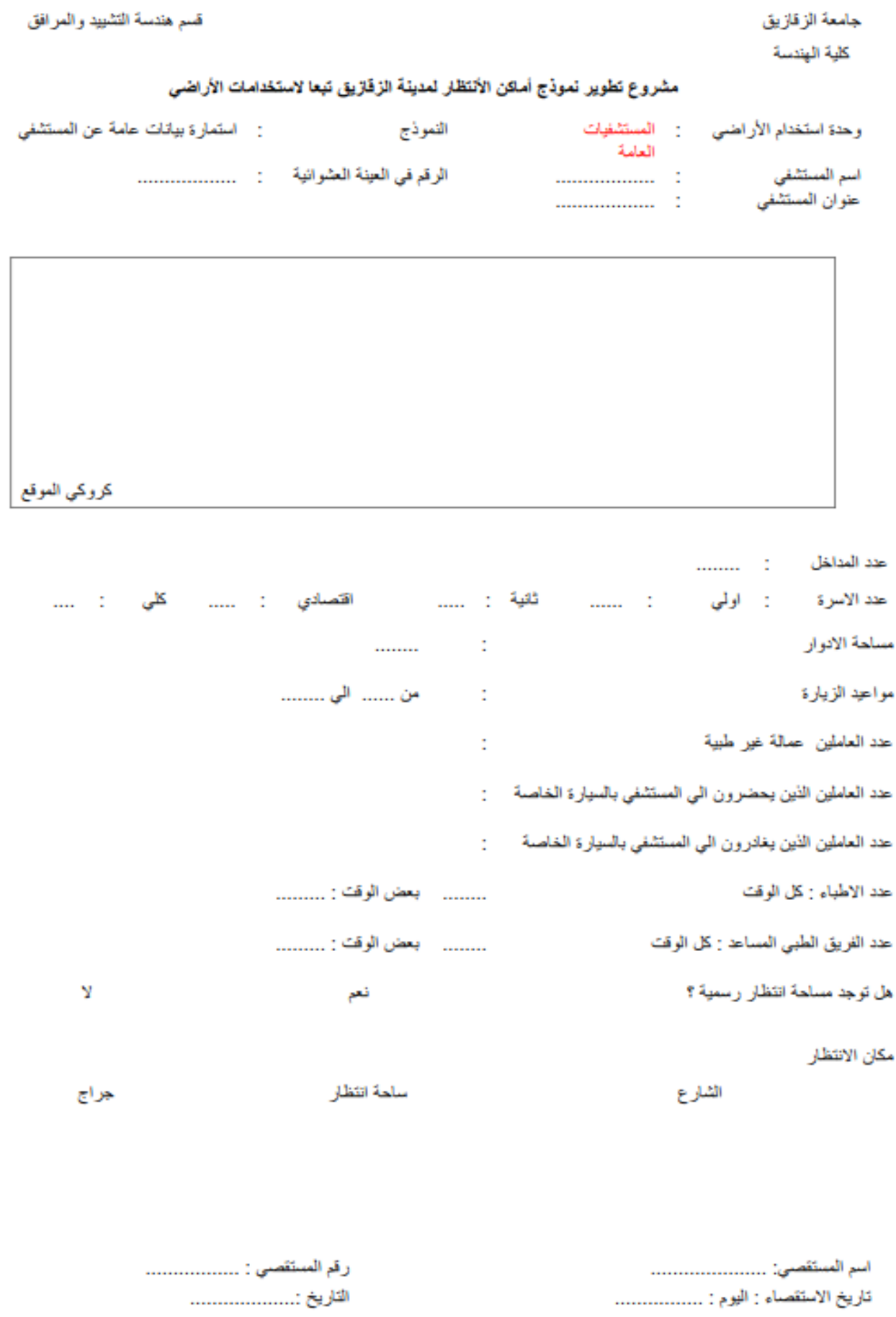

Figure 3 Inventory data of public hospital form designed for parking demand rate of investigated public hospitals in Zagazig city, Egypt

\section{RESULTS AND DISCUSSION}

The results of parking volumes, parking cumulative, and parking rates of each of studied public hospital are presented and discussed in this section. Then, deduced parking rates of 
investigated public hospitals are determined and evaluated. Deduced parking rates are compared with the international rates. The following subsections illustrate analysis of these titles.

\subsection{Analysis of Parking Volume Results}

Table (1) presents total parking volumes during $8 \mathrm{hr}$ and the average hourly parking volume values for the investigated hospitals, respectively. Also, total gross floor area, and number of beds for each of public hospital are shown in the same table. Analyzing the results shows that total parking volumes of surveyed hospitals vary from 2010 to 2790 private vehicles per counting period. Knowing that private vehicle includes private car, taxi, and microbus. The maximum total parking volume during $8 \mathrm{hr}$ is 2790 private vehicles for compound Zagazig university hospitals 1 .This may be due to its highest number of beds as well as its highest total gross floor area. Also, it is found that compound Zagazig university hospitals 1 includes unique medical specialties units at the level of Sharkia governorate. Furthermore, the total parking volume of El Ahrar (2172 private vehicles) is more than parking volume of compound Zagazig university hospitals 2 (2010 private vehicles) in spite of its smaller number of beds (608 beds). It found that El Ahrar involves other medical activities such as medical commission. It can be concluded the following: (a) parking volume increases with the increase of public hospital number of beds or total gross floor area, (b) parking volume increases with increasing area of service region, and (c) parking volume increases for any additional activities of hospital other than its common activity.

Table 1 Characteristics and parking volume for each of investigated public hospital

\begin{tabular}{|l|c|c|c|c|}
\hline \multicolumn{1}{|c|}{ Name of hospital } & $\begin{array}{c}\text { Total volume } \\
\text { (private vehicle } \\
\text { per 8 hours) }\end{array}$ & $\begin{array}{c}\text { Average volume } \\
\text { (private vehicle /hr) }\end{array}$ & $\begin{array}{c}\text { Total gross } \\
\text { floor area } \\
\left(\mathbf{1 0 0} \mathbf{~ m}^{\mathbf{2}} \text { ) }\right.\end{array}$ & $\begin{array}{c}\text { Number of } \\
\text { beds }\end{array}$ \\
\hline $\begin{array}{l}\text { Compound Zagazig } \\
\text { university hospitals 1 }\end{array}$ & 2790 & 349 & 696.96 & 985 \\
\hline $\begin{array}{l}\text { Compound Zagazig } \\
\text { university hospitals 2 }\end{array}$ & 2010 & 251 & 364.67 & 766 \\
\hline El Ahrar & 2172 & 272 & 502.84 & 608 \\
\hline
\end{tabular}

The main work in this study is to collect number of private vehicles occupied an area in parking area of each of investigated hospital. The amount of parking in this study is surveyed during regular time interval (one hour) on two weekdays for one week. Counting duration of parking carried out between 8:00 A.M. and 4:00 P.M. The results are shown in Figure (4) . The figure shows that parking accumulation increases during the interval from 8 A.M. to 12.00 P.M. for all investigated public hospitals. Considerable increasing of parking accumulation is noticed in the period between 8.00 A.M. and 9.00 A.M. for all public hospitals in the study. The maximum rates of increasing are noted in the period from 9.00 A.M. to 10.00 A.M. It is also noted that, the increasing of parking accumulation decreases in the interval 10.00 A.M. to 12.00 P.M. for all studied public hospitals. Furthermore, parking accumulation starts in the decreasing during the interval from 8.00 A.M. to 12.00 P.M. for all investigated hospitals. But, parking accumulation decreases during the interval from 12.00 P.M. to 4.00 P.M. for all surveyed public hospitals. It decreases with a considerable rate during the interval from 12.00 P.M. to 1.00 P.M. then, it decreases with a drastically rates during 13.00 P.M to 14.00 P.M.. Finally, decreasing values of parking accumulation in the period between 14.00 P.M. and 16.00 P.M. becomes very low. It can be concluded that peak values of parking accumulation is occurred at the time interval between 11:00 A.M. and 12:00 A.M. for all investigated hospitals. Usual medical services such as external polyclinics starting in this time interval may be the reason. 
Metwally G. M. Altaher, Mohamed Abdelghany Elsayed and Ali Ramadan Ibrahim

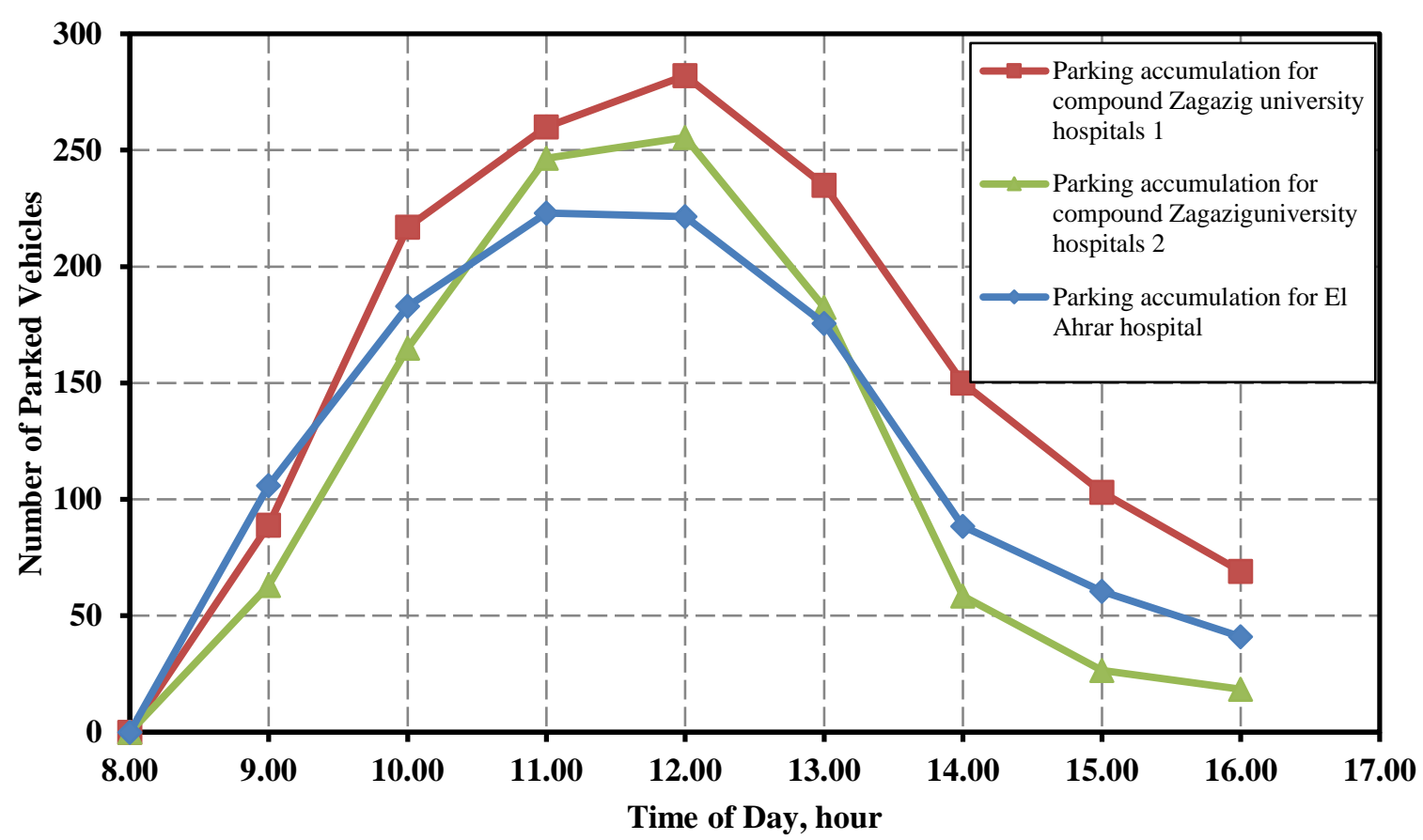

Figure 4 Parking accumulation for all surveyed hospitals.

\subsection{Calculation and Analysis of Parking Rate of Studied Public Hospitals}

Parking rate is maximum parking demand during peak period represents the numerator of parking rates of investigated public hospitals divided by number of beds or total gross floor area. Parking rate is the dependent variable in this study, while number of beds or total gross floor area of public hospitals are considered independent variables. Table (2) presents the maximum parking accumulation of investigated public hospitals. Peak values of parking accumulation of studied public hospitals are 282, 224, and 256 private vehicle for compound Zagazig university hospitals 1, compound Zagazig university hospitals 2, and El Ahrar hospital, respectively. The highest parking accumulation is 282 private vehicle for compound Zagazig university hospitals 1 . This may be due to its highest number of beds (985 bed). Furthermore, the maximum parking accumulation of El Ahrar (256 private vehicles) is more than maximum parking accumulation of compound Zagazig university hospitals 2 ( 224 private vehicles) in spite of its lower capacity (608 beds). This emphasizes that adding special activities such as medical commission to normal activity increase number of parked private vehicles for El Ahrar hospital.

Table 2 Maximum parking accumulation for each of investigated public hospital

\begin{tabular}{|l|c|}
\hline \multicolumn{1}{|c|}{ Name of hospital } & $\begin{array}{c}\text { Maximum parking accumulation, } \\
\text { (private vehicle) }\end{array}$ \\
\hline Compound Zagazig university hospitals 1 & 282 \\
\hline Compound Zagazig university hospitals 2 & 224 \\
\hline El Ahrar & 256 \\
\hline
\end{tabular}

Table (3) presents parking demand rates of each of surveyed public hospitals. Average and coefficient of variance of parking rates of the total sample is also presented in the table. Firstly, least coefficients of variance of total sample are 0.206 , and 0.228 considering number of beds or total gross floor area of public hospitals are considered independent variables, respectively. These values are considered tend to zero. So, according to statistical analysis, all parking rated calculated in this study are considered suitable. Analyzing the results of parking 
rates values shows that parking rates values based on $100 \mathrm{~m}^{2}$ of total gross floor area is more than parking rates based on number of bed. This may be due to $100 \mathrm{~m}^{2}$ of public hospital area may include more than one bed. Parking rate of El Ahrar hospital is the highest (0.421 private vehicle per bed) in spite of its smaller number of beds (608 beds). Special activities may be the cause. Parking rates based on total gross floor area for compound Zagazig university hospitals 2 is the maximum (0.614private vehicle per bed). Its area comparing to number of beds may be the cause. Average parking rate of the total investigated public hospitals is 0.333 per number of bed.

Table 3 Parking demand rates for investigated public hospitals

\begin{tabular}{|l|c|c|}
\hline \multirow{2}{*}{ Name of hospital } & \multicolumn{2}{c|}{ Rate of parking per independent variable } \\
\cline { 2 - 3 } & Per number of beds & Per 100 $\mathbf{~ m}^{\mathbf{2}}$ \\
\hline Compound Zagazig university hospitals 1 & 0.286 & 0.405 \\
\hline Compound Zagazig university hospitals 2 & 0.292 & 0.614 \\
\hline El Ahrar & 0.421 & 0.509 \\
\hline Average & 0.333 & 0.509 \\
\hline Coefficient of variance & 0.228 & 0.206 \\
\hline
\end{tabular}

\subsection{Evaluation of Deduced Parking Rates and International Rates}

Figure (5) illustrates parking rates of public hospitals of investigated public hospitals in Zagazig city, Egypt, and Abu Dhabi manual. Analysis of this figure shows that average parking rate of investigated public hospitals ;of investigated public hospitals in Zagazig city, Egypt based on number of bed ( 0.333 private vehicle per bed) is more than parking rate of private hospital of Abu Dhabi (0.281 vehicle per bed). That is traffic needing the health facility is often uses private motor regarding to the nature of the patients of Zagazig city. Table (4): presents ITE parking rate and investigated public hospitals in Zagazig city, Egypt. Parking rate value of investigated public hospitals in Zagazig city of parking rate $(0.333$ private vehicle per bed ) is less than value of ITE rate (3.47 vehicle per bed). High ownership, high average income of American citizen comparing to Egyptian citizen may be the reasons.

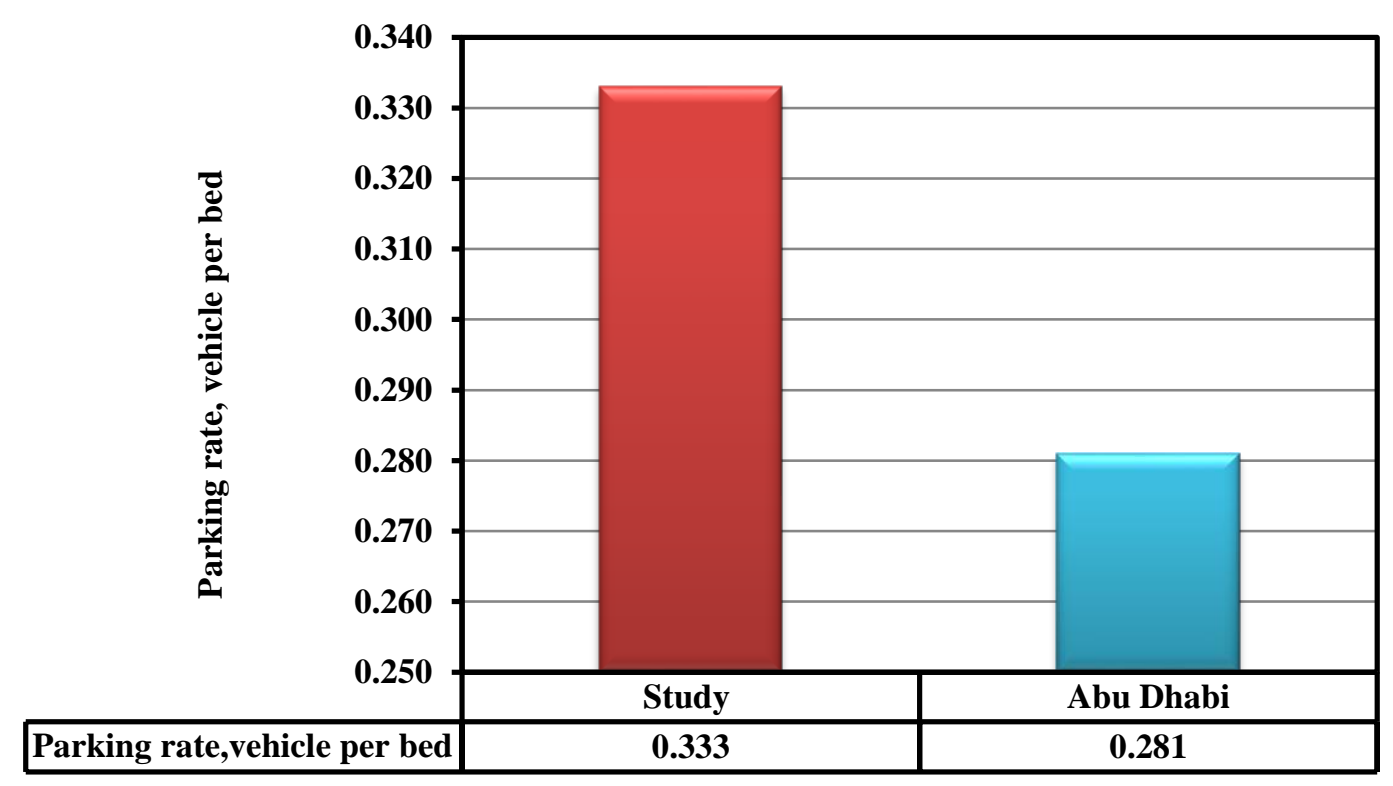

Figure 5 Parking rates of public hospital land use based on number of bed for of investigated public hospitals in Zagazig city, Egypt and Abu Dhabi manual 
Table 4 Parking rates of public hospital activity based on number of bed for of investigated public hospitals in Zagazig city, Egypt and ITE manual

\begin{tabular}{|c|c|}
\hline \multicolumn{2}{|c|}{$\begin{array}{c}\text { Parking rate } \\
\text { (Vehicle per bed ) }\end{array}$} \\
\hline Deduced study rate & ITE rate \\
\hline 0.333 & 3.47 \\
\hline
\end{tabular}

\section{CONCLUSIONS AND RECOMMENDATIONS}

Analyzing study results, the following can be concluded:

- Parking volume increases with the increase of public hospital number of beds or total gross floor area.

- Parking volume increases with increasing area of service region.

- Parking volume increases for any additional activities of hospital other than its common activity.

- Parking rates values based on $100 \mathrm{~m}^{2}$ of total gross floor area is more than parking rates based on number of bed.

- Parking rate of El Ahrar hospital is the highest ( 0.421 private vehicle per bed) in spite of its smaller number of beds ( 608 beds).

- Parking rates based on total gross floor area for compound Zagazig university hospitals 2 is the maximum (0.614 private vehicle per bed). Its area comparing to number of beds may be the cause.

- Average parking rate of the total investigated public hospitals is 0.333 per number of bed.

- Average parking rate of investigated public hospitals; of investigated public hospitals in Zagazig city, Egypt based on number of bed private vehicle per bed is more than parking rate of private hospital of Abu Dhabi.

- Parking rate value of investigated public hospitals in Zagazig city is less than value of ITE rate.

- The average parking rates of public hospitals in Zagazig is 0.509 private vehicle per $100 \mathrm{~m}^{2}$.

- It is very much recommended to update the results of the present work every 3 - 5 years. This can be done even on smaller but representative sample size. Such updating rates is very important in order to enhance the obtained rates and to monitor their change as time elapses. In order to reach comprehensive and detailed understanding of parking rates and the involved factors, the following further research is recommended.

- It can be useful to undertake detailed comparative analysis of the different parking rates for the different land use activities. It can be useful for situations when the decision maker is faced with a choice of developing on of a set of alternative different land use activities.

\section{REFERENCES}

[1] Metwally G. M. Altaher, Ahmed Mohamady Abdallah, Mohamed Abdelghany Elsayed, Abd El-Rahman Baz Abd El-Samii Mahfouz (2019). Traffic Congestion Control for Unplanned Cities. PhD thesis, Zagazig University.

[2] https://www.tomtom.com/en_gb/traffic-index/ranking, 19/7/2019. 
[3] Metwally G. M. Altaher, Ahmed Mohamady Abdallah, Mohamed Abdelghany Elsayed, Abd El-Rahman Baz Abd El-Samii Mahfouz (2019). Traffic Congestion Control for Unplanned Cities. International Journal of Civil Engineering and Technology. Volume 10, Issue 06, June 2019, pp. 528-540

[4] Okail, O., Mohamady, A. \& El-Gamal, E. (2019). Parking Demand Rates for Some Selected Land Uses in Egyptian Cities. International Journal of Engineering and Advanced Technology (IJEAT)

[5] Putu Alit Suthanaya (2017). Development of Parking Demand Model for Private Hospital in Developing Country (Case Study of Denpasar City, Indonesia). Journal of Sustainable Development.

[6] Department of Transport of Abu Dhabi (2012). Trip Generation and Parking Rates Manual for Emirate of Abu Dhabi. Abu Dhabi, UAE.

[7] Institute Of Transportation Engineers (ITE) (2010). Parking Generation (Report No. IR034C). Washington, D.C., USA.

[8] Development research and technological planning center (1994). Trip generation by land use types in greater Cairo. Cairo: Academy of scientific research and technology transport research council.

[9] Egyptian Code for Urban and Rural Road Works (2007). Code No. 104, Vol. 10, Traffic Engineering, $2^{\text {nd }}$ edition (in Arabic).

[10] Khan, K, Bukhari, S. M. A., Akram, W., Anjum, M., \& Raza, A. (2015). Parking demand model for hospitals in Punjab: A case study of Lahore: Pakistan Urban Forum. Pakistan.

[11] Douglass, M., \& Abley, S. (2011). Trips and parking related to land use, NZ Transport Agency research report 453. New Zealand: NZ Transport Agency. 